\title{
Factors Influencing Choice of Medical Specialty among Ophthalmology and Non- Ophthalmology Residency Applicants
}

\author{
David Cui, BA ${ }^{1}$ Andreas M. Wingert ${ }^{2}$ Ingrid U. Scott, MD, MPH ${ }^{3,4}$
}

1 Penn State College of Medicine, Hershey, Pennsylvania

2 Haverford College, Haverford, Pennsylvania

3 Department of Ophthalmology, Penn State College of Medicine, Hershey, Pennsylvania

${ }^{4}$ Department of Public Health Sciences, Penn State College of Medicine, Hershey, Pennsylvania

J Acad Ophthalmol 2021;13:e129-e137.

\begin{abstract}
Address for correspondence Ingrid U. Scott, MD, MPH, Jack and Nancy Turner Professor of Ophthalmology, Professor of Public Health Sciences, Penn State College of Medicine, 500 University Dr, HU19, Hershey, PA 17033-0850 (e-mail: iscott@pennstatehealth.psu.edu).
\end{abstract}

\begin{abstract}
Keywords

- ophthalmology applicant

- residency applicant

- specialty selection

- motivators

- exposure

Objective The study aimed to investigate factors influencing choice of specialty among ophthalmology and non-ophthalmology residency applicants.

Patients and Methods Anonymous, web-based surveys were distributed through REDCap to the 2019 to 2020 residency applicants to the Penn State Department of Ophthalmology and, as a control group, Penn State medical students applying to nonophthalmology residencies for the 2019 to 2020 cycle. The primary outcome was factors that influenced specialty choice among ophthalmology versus non-ophthalmology applicants. Secondary outcomes include hours of exposure to applicants' selected specialty in the medical school preclinical curriculum, and proportion of ophthalmology versus non-ophthalmology applicants who decided on, or developed a strong interest in, their specialty prior to clinical rotations.

Results Surveys were completed by $203 / 441$ (46.0\%) ophthalmology and 85/139 (61.1\%) non-ophthalmology applicants. Fewer than 20 hours of exposure to an applicant's selected specialty were provided in the medical school preclinical curriculum for $86.7 \%$ of ophthalmology and $42.4 \%$ of non-ophthalmology applicants $(p<0.001)$. Ophthalmology applicants decided on, or developed a strong interest in, their selected specialty before clinical rotations at a similar rate to non-ophthalmology applicants ( 60.6 vs. $58.8 \%$, respectively). Factors influencing specialty choice cited most commonly by ophthalmology applicants include professional satisfaction (94.1\%), performing surgeries/procedures $(92.6 \%)$, personal fit with specialty (91.1\%), work-life balance $(91.1 \%)$, and ability to see patients in a clinic setting $(90.6 \%)$, compared to personal fit with specialty $(95.3 \%) \%$, clinical rotation in selected specialty (95.3\%), professional satisfaction (91.8\%), intellectual stimulation (89.4\%), and subinternship or away rotation (89.4\%) among non-ophthalmology applicants.
\end{abstract}

received

October 6, 2020

accepted after revision

December 15, 2020
DOI https://doi.org/ $10.1055 / \mathrm{s}-0041-1728644$. ISSN 2475-4757. (c) 2021. The Author(s).

This is an open access article published by Thieme under the terms of the Creative Commons Attribution-NonDerivative-NonCommercial-License, permitting copying and reproduction so long as the original work is given appropriate credit. Contents may not be used for commercial purposes, or adapted, remixed, transformed or built upon. (https://creativecommons.org/ licenses/by-nc-nd/4.0/)

Thieme Medical Publishers, Inc., 333 Seventh Avenue, 18th Floor, New York, NY 10001, USA 
Conclusion Professional satisfaction and personal fit with specialty were among the most commonly cited factors influencing specialty choice for both groups. Other factors cited most frequently by ophthalmology applicants include performing surgeries/procedures, work-life balance, and ability to see patients in a clinic setting. Despite limited ophthalmology exposure in medical school preclinical curricula, ophthalmology applicants decided on, or developed a strong interest in, their selected specialty before clinical rotations at a rate similar to non-ophthalmology applicants.

In 2019, residency applicants to ophthalmology comprised $1.69 \%$ of the total applicant pool applying to any residency program in the United States. ${ }^{1,2}$ Acceptance into ophthalmology residency is competitive, with $74.6 \%$ of ophthalmology residency applicants in 2019 matching successfully compared to $79.6 \%$ for all specialties, despite ophthalmology applicants having a higher average United States Medical Licensing Examination Step 1 score. ${ }^{1,2}$ There are multiple publications reporting why ophthalmology may be an attractive career choice. ${ }^{3-6}$ A 2020 national survey of physicians in any specialty found that ophthalmologists have high job satisfaction, with nearly $95 \%$ of ophthalmologists reporting they would choose ophthalmology as their specialty again if given the opportunity. ${ }^{3}$ The survey also reported that ophthalmologists spend the least amount of time of any specialty surveyed on paperwork and administration, which would allow more time to be spent on patient care. ${ }^{3}$ Further, while poor lifestyle quality is frequently identified as a disincentive for students pursuing surgery, ${ }^{7,8}$ a survey of medical students at a single institution found that none of the 84 respondents identified this as a deterrent to pursuing ophthalmology. ${ }^{4}$ Two studies on medical student career choice also identified that students commonly associate ophthalmology as a specialty with a controllable and favorable lifestyle.,6

There is limited published information on why medical students in the United States decide to pursue ophthalmology. There are published studies that investigate why medical students in the United States pursue other specialties, including surgical subspecialties, ${ }^{7-10}$ and studies reporting why medical students in countries outside the United States apply to ophthalmology. ${ }^{11-13}$ To our knowledge and based on a computerized search of the PubMed database, there is only one published study which investigates why medical students in the United States apply to ophthalmology; however, the generalizability of this study to current applicants is limited due to the survey being conducted 30 years ago. ${ }^{14}$ There is also one published study that evaluates how medical students perceive ophthalmology as a career; however, the population surveyed in that study consists of medical students who did not plan on applying to ophthalmology. 4

Several studies have demonstrated that increased exposure to a specialty in medical school increases the likelihood that a student will apply to that specialty, ${ }^{4,10,15,16}$ with lack of exposure to ophthalmology being cited as a leading cause of medical students not applying to ophthalmology. ${ }^{4,16}$ Recent studies conclude that ophthalmology content in required medical school curricula has decreased, ${ }^{17-19}$ particularly required clinical rotations, which decreased from $68 \%$ of surveyed medical schools in 2000 to $16 \%$ (15/95) in 2018. ${ }^{18,19}$ Despite the decrease in required clerkships, the proportion of U.S. medical schools with required preclinical ophthalmology exposure has remained constant in 2018 (88/95, 92.6\%) compared to 2014 (104/109, 95.4\%). ${ }^{18,19}$ These findings may be concerning, as evidence suggests that even a 1-day ophthalmology experience during the clinical years can increase ophthalmology knowledge and clinical skills. ${ }^{20}$ Many primary care providers, such as those in internal medicine, report low confidence in performing ophthalmic examinations and treating ocular complaints, which can comprise up to $5 \%$ of their visits, and a strong majority (380/412, 92.2\%) reported that they received fewer than 10 hours of ophthalmology education in residency. ${ }^{21}$ Published studies on ophthalmology exposure in medical school have only surveyed leaders in medical education and not medical students or ophthalmology residency applicants. ${ }^{16,17,19}$

The purpose of our study is to investigate factors influencing choice of specialty among ophthalmology and nonophthalmology residency applicants.

\section{Patients and Methods}

The study was approved by the Penn State Institutional Review Board and conducted in accordance with the Declaration of Helsinki. Two surveys were constructed based on existing literature and discussion with colleagues involved in medical and residency education. The surveys were pre-tested and reviewed by members of the study team, and revised based on feedback received. One survey ( - Fig. 1), designed for the 2019 to 2020 residency applicants to the Penn State Department of Ophthalmology, assessed prior exposure to ophthalmology and reasons for pursuing ophthalmology. A second survey (-Fig.2), designed for medical students in the graduating class of 2020 at the Penn State College of Medicine who did not apply for ophthalmology residency, differed from the first survey in that wording was revised to reflect the respondent's selected specialty instead of ophthalmology. The non-ophthalmology applicants served as a control group to compare differences between ophthalmology and non-ophthalmology applicants with respect to exposure to their selected specialty and reasons for specialty selection.

The surveys were constructed by using the secure online application REDCap hosted at Penn State College of Medicine. ${ }^{22}$ A REDCap-generated email was used to distribute the surveys in January 2020. Nonresponders were identified anonymously by using the REDCap system and were sent reminder emails, with the last reminder email sent in May 2020. 
- What is your age?

- What is your gender?

- How do you self-identify?

- American Indian or Alaska Native

- Asian

- Black

- Hispanic or Latino

- Pacific Islander or Native Hawaiian

- White

- Other

- Choose not to identify or N/A

- When did you develop a strong interest in, or decide to pursue, your medical specialty?

- Before medical school

- During medical school before clinical rotations

- During or after medical school clinical rotations

- How much education in ophthalmology did you receive as part of your medical school's official preclinical curriculum?

How did the following factors influence your decision to pursue ophthalmology? Please choose "Not Applicable" if you did not have that exposure or factor.

\begin{tabular}{|l|l|l|l|l|l|l}
\hline & $\begin{array}{l}\text { Not } \\
\text { Applicable }\end{array}$ & $\begin{array}{l}\text { Strong } \\
\text { Negative } \\
\text { Influence }\end{array}$ & $\begin{array}{l}\text { Negative } \\
\text { Influence }\end{array}$ & $\begin{array}{l}\text { No } \\
\text { Influence }\end{array}$ & $\begin{array}{l}\text { Positive } \\
\text { Influence }\end{array}$ & $\begin{array}{l}\text { Strong } \\
\text { Positive } \\
\text { Influence }\end{array}$ \\
\hline $\begin{array}{l}\text { Exposure to } \\
\text { ophthalmology prior to } \\
\text { medical school }\end{array}$ & & & & & \\
\hline $\begin{array}{l}\text { Exposure to } \\
\text { ophthalmology during } \\
\text { medical school prior to } \\
\text { clinical rotations }\end{array}$ & & & & & & \\
\hline $\begin{array}{l}\text { An ophthalmology clinical } \\
\text { rotation during medical } \\
\text { school }\end{array}$ & & & & & \\
\hline $\begin{array}{l}\text { An ophthalmology sub- } \\
\text { internship or an away } \\
\text { rotation }\end{array}$ & & & & & \\
\hline $\begin{array}{l}\text { An ophthalmology } \\
\text { department affiliated with } \\
\text { your medical school }\end{array}$ & & & & & \\
\hline $\begin{array}{l}\text { An ophthalmology faculty } \\
\text { mentor }\end{array}$ & & & & & \\
\hline $\begin{array}{l}\text { An ophthalmology interest } \\
\text { group at your medical } \\
\text { school }\end{array}$ & & & & & & \\
\hline $\begin{array}{l}\text { Ophthalmology research } \\
\text { experience }\end{array}$ & & & & & \\
\hline $\begin{array}{l}\text { Volunteering or public } \\
\text { health experience in } \\
\text { ophthalmology }\end{array}$ & & & & & \\
\hline
\end{tabular}

Fig. 1 Survey distributed to the 2019 to 2020 residency applicants to the Penn State Department of Ophthalmology assessing exposure to ophthalmology and factors influencing decision to pursue ophthalmology. 


\begin{tabular}{|l|l|l|l|l|l|}
\hline $\begin{array}{l}\text { Family member who is an } \\
\text { ophthalmologist }\end{array}$ & & & & & \\
\hline $\begin{array}{l}\text { Family member who is not } \\
\text { an ophthalmologist but } \\
\text { works in the ocular field } \\
\text { (optometrist, orthoptist, } \\
\text { technician, etc) }\end{array}$ & & & & & \\
\hline $\begin{array}{l}\text { Personal or family history } \\
\text { of ocular disease }\end{array}$ & & & & & \\
\hline $\begin{array}{l}\text { Ability to perform } \\
\text { procedures or surgeries }\end{array}$ & & & & & \\
\hline $\begin{array}{l}\text { Ability to see patients in a } \\
\text { clinic setting }\end{array}$ & & & & & \\
\hline $\begin{array}{l}\text { Intellectual } \\
\text { stimulation/challenging } \\
\text { cases }\end{array}$ & & & & & \\
\hline Professional satisfaction & & & & & \\
\hline $\begin{array}{l}\text { Personal fit with the } \\
\text { specialty }\end{array}$ & & & & & \\
\hline Work-life balance & & & & & \\
\hline Salary or earning potential & & & & & \\
\hline Job market & & & & & \\
\hline Prestige or reputation & & & & & \\
\hline $\begin{array}{l}\text { Specific patient population } \\
\text { or disease(s) treated } \\
\text { unique to ophthalmology }\end{array}$ & & & & & \\
\hline
\end{tabular}

Fig. 1 (Continued)

Comparisons between the two cohorts were made by using STATA version 15.1 for statistical analysis (STATA Corp, College Station, Texas, United States). Student's $t$ test was used to assess differences in the continuous variable of respondent age. Pearson's Chi-square test was used to compare frequency/percentage differences for all categorical variables: presence of specialty-specific exposure, whether a respondent stated a factor had a "positive influence" or "strongly positive influence" on pursuing their selected specialty and demographic information. The $p$-values $\leq 0.05$ were considered statistically significant.

\section{Results}

Surveys were completed by 203/441 (46.0\%) ophthalmology and 85/139 (61.1\%) non-ophthalmology applicants. Demographic information is summarized in - Table 1. There was no significant difference between the two groups with respect to age, race and ethnicity, and gender ( $p>0.05$, - Table 1).

Fewer than 20 hours of exposure to an applicant's selected specialty were provided in the medical school preclinical curriculum for $86.7 \%$ of ophthalmology applicants and $42.4 \%$ of non-ophthalmology applicants $(p<0.001)$. This exposure includes the education received by an applicant in their medical school's official preclinical curriculum and does not include shadowing, research, or other initiatives from the applicants themselves during the preclinical years. Oph- thalmology applicants decided on, or developed a strong interest in, their selected specialty before clinical rotations at a rate similar to that of non-ophthalmology applicants (60.6 vs. $58.8 \%$, respectively; $p=0.780$ ).

- Table 2 compares the exposure of ophthalmology and non-ophthalmology 2019 to 2020 residency applicants to their selected specialty. Exposures to ophthalmology cited most frequently by ophthalmology applicants include a clinical rotation (99.0\%), access to an ophthalmology faculty mentor (95.6\%), participating in ophthalmology research (95.1\%), and a subinternship or away rotation in ophthalmology (89.7\%; - Table 2). Exposures to their selected specialty cited most frequently by non-ophthalmology applicants include a clinical rotation (100\%), a residency program of the selected specialty at their medical school (96.5\%), and any exposure in their selected specialty before clinical rotations (92.9\%; - Table 2). The exposure experiences that differed significantly between the two groups were the existence of a residency program of the chosen specialty affiliated with the applicant's medical school (86.2\% ophthalmology vs. 96.5\% non-ophthalmology; $p=0.010)$ and research experience (95.1\% ophthalmology vs. $84.7 \%$ non-ophthalmology; $p=0.003$; - Table 2 ).

- Table 3 compares factors that influenced ophthalmology and non-ophthalmology applicants to pursue their respective specialties. Factors cited most frequently by ophthalmology applicants as having a "positive" or "strongly 
- What is your age?

- What is your gender?

- How do you self-identify?

- American Indian or Alaska Native

- Asian

- Black

- Hispanic or Latino

- Pacific Islander or Native Hawaiian

- White

- Other

- Choose not to identify or N/A

- Which residency are you applying to?

- When did you develop a strong interest in, or decide to pursue, your medical specialty?

- Before medical school

- During medical school before clinical rotations

- During or after medical school clinical rotations

- How much education in your selected specialty did you receive as part of your medical school's official preclinical curriculum?

- How did the following factors influence your decision to pursue your chosen medical specialty? Please choose "Not Applicable" if you did not have that exposure or factor.

\begin{tabular}{|l|l|l|l|l|l|l|}
\hline & $\begin{array}{l}\text { Not } \\
\text { Applicable }\end{array}$ & $\begin{array}{l}\text { Strong } \\
\text { Negative } \\
\text { Influence }\end{array}$ & $\begin{array}{l}\text { Negative } \\
\text { Influence }\end{array}$ & $\begin{array}{l}\text { No } \\
\text { Influence }\end{array}$ & $\begin{array}{l}\text { Positive } \\
\text { Influence }\end{array}$ & $\begin{array}{l}\text { Strong } \\
\text { Positive } \\
\text { Influence }\end{array}$ \\
\hline $\begin{array}{l}\text { Exposure to your specialty } \\
\text { prior to medical school }\end{array}$ & & & & & \\
\hline $\begin{array}{l}\text { Exposure to your specialty } \\
\text { during medical school } \\
\text { prior to clinical rotations }\end{array}$ & & & & & \\
\hline $\begin{array}{l}\text { A clinical rotation in your } \\
\text { specialty during medical } \\
\text { school }\end{array}$ & & & & & \\
\hline $\begin{array}{l}\text { A sub-internship or an } \\
\text { away rotation in your } \\
\text { specialty }\end{array}$ & & & & & \\
\hline $\begin{array}{l}\text { A residency program in } \\
\text { your given specialty } \\
\text { associated with Penn State }\end{array}$ & & & & & & \\
\hline $\begin{array}{l}\text { A faculty mentor in your } \\
\text { specialty }\end{array}$ & & & & & & \\
\hline $\begin{array}{l}\text { An interest group of your } \\
\text { specialty at Penn State }\end{array}$ & & & & & & \\
\hline $\begin{array}{l}\text { Research experience in } \\
\text { your specialty }\end{array}$ & & & & & \\
\hline $\begin{array}{l}\text { Volunteering or public } \\
\text { health experience in your } \\
\text { specialty }\end{array}$ & & & & & \\
\hline $\begin{array}{l}\text { Family member who is a } \\
\text { physician in your specialty }\end{array}$ & & & & & \\
\hline
\end{tabular}

Fig. 2 Survey distributed to the graduating class of 2020 at the Penn State College of Medicine assessing exposure to selected specialty and factors influencing decision to pursue selected specialty. 


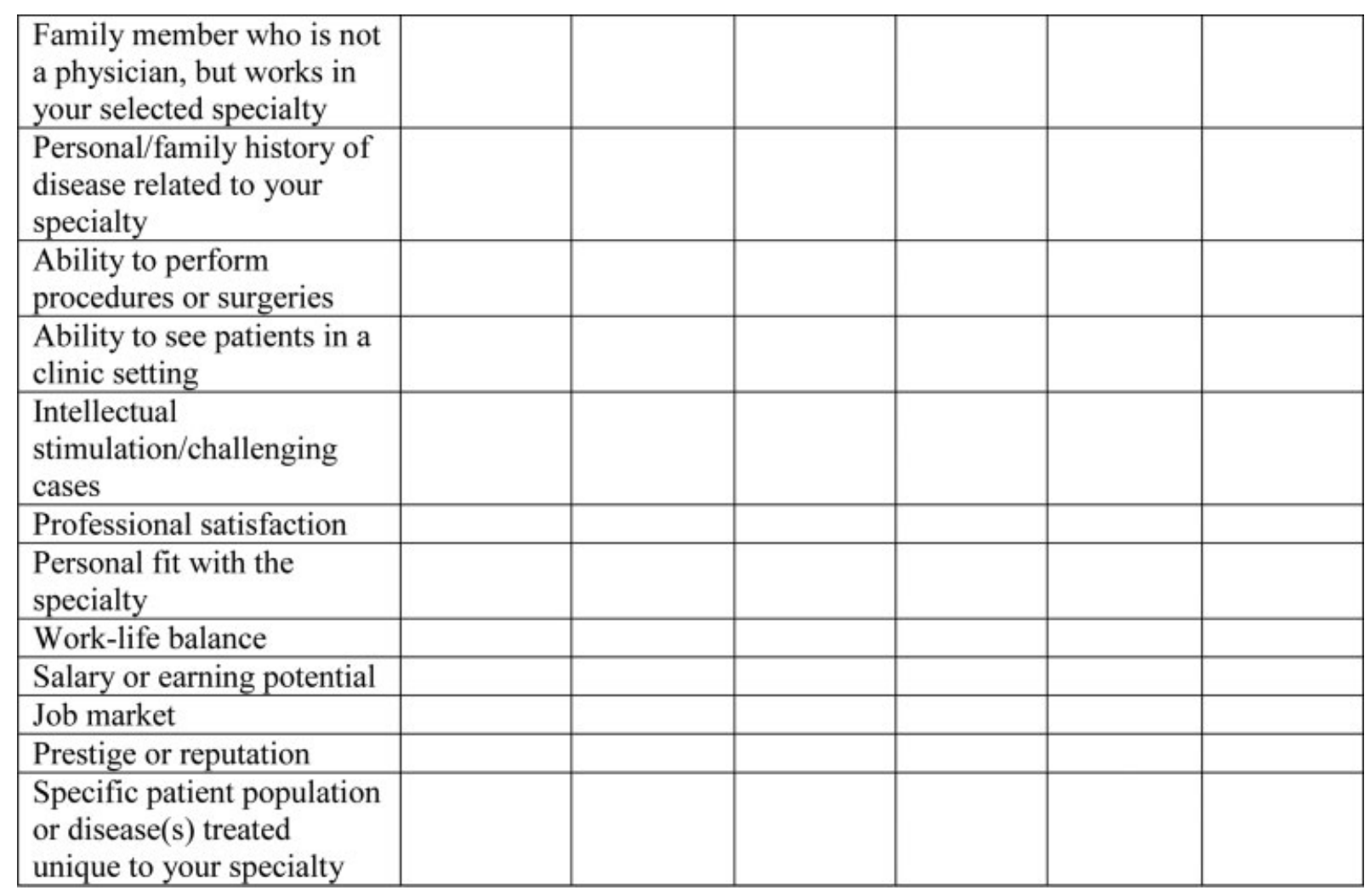

Fig. 2 (Continued)

Table 1 Demographic characteristics of 2019 to 2020 ophthalmology and non-ophthalmology residency applicants

\begin{tabular}{|c|l|l|l|}
\hline & $\begin{array}{l}\text { Ophthalmology } \\
\text { applicants } \\
(\boldsymbol{n = 2 0 3 )}\end{array}$ & $\begin{array}{l}\text { Non- } \\
\text { ophthalmology } \\
\text { applicants } \\
(\boldsymbol{n}=85)\end{array}$ & $p$-Value \\
\hline $\begin{array}{l}\text { Average } \\
\text { age (SD) }\end{array}$ & $26.9(2.1)$ & $27.3(2.9)$ & 0.191 \\
\hline $\begin{array}{l}\text { Race and } \\
\text { ethnicity }\end{array}$ & & & 0.269 \\
\hline Asian & $49(24.1 \%)$ & $12(14.1 \%)$ & \\
\hline Black & $10(4.9 \%)$ & $3(3.5 \%)$ & \\
\hline Hispanic & $19(9.4 \%)$ & $6(7.1 \%)$ & \\
\hline White & $121(59.6 \%)$ & $62(72.9 \%)$ & \\
\hline Other & $4(2.0 \%)$ & $2(2.4 \%)$ & \\
\hline Gender & & & 0.447 \\
\hline Male & $115(56.7 \%)$ & $44(51.8 \%)$ & \\
\hline Female & $88(43.3 \%)$ & $41(48.2 \%)$ & \\
\hline
\end{tabular}

Abbreviation: SD, standard deviation.

positive" influence on choice of specialty include professional satisfaction (94.1\%), ability to perform surgeries/procedures (92.6\%), personal fit with specialty (91.1\%), work-life balance $(91.1 \%)$, and ability to see patients in a clinic setting (90.6\%), compared to personal fit with specialty (95.3\%)\%, clinical rotation in selected specialty (95.3\%), professional satisfaction (91.8\%), intellectual stimulation (89.4\%), and subinternship or away rotation (89.4.4\%) among non-ophthalmology applicants (-Table 3 ). Influencing factors that differed significantly between the two groups include residency program of chosen specialty affiliated with the applicant's medical school (70.9\% ophthalmology vs. $49.4 \%$ nonophthalmology, $p<0.001)$, faculty mentor in selected specialty (86.7\% ophthalmology vs. $72.9 \%$ non-ophthalmology, $p=0.005)$, research experience in chosen specialty $(69.0 \%$ ophthalmology vs. $32.9 \%, p<0.001)$, ability to perform surgeries/procedures (92.6\% ophthalmology vs. $68.2 \%$ nonophthalmology, $p<0.001$ ), seeing patients in a clinic setting (90.6\% ophthalmology vs. $67.0 \%$ non-ophthalmology, $p<0.001)$, work-life balance $(91.1 \%$ ophthalmology vs. $76.5 \%$ non-ophthalmology, $p<0.001)$, and specialty prestige/reputation (46.8\% ophthalmology vs. $31.8 \%$ nonophthalmology, $p=0.019$; - Table 3).

\section{Discussion}

Professional satisfaction and personal fit with specialty were among the most commonly cited factors influencing specialty choice among both ophthalmology and non-ophthalmology applicants. Other factors cited most frequently by ophthalmology applicants include performing surgeries/ procedures, work-life balance, and ability to see patients in a clinic setting. The factors influencing specialty choice cited most commonly by the ophthalmology applicants in the current study are similar to the influencing factors identified in a study of U.S. ophthalmology residency applicants 
Table 2 Exposure of 2019 to 2020 ophthalmology and non-ophthalmology residency applicants to their selected specialty

\begin{tabular}{|c|c|c|c|}
\hline & $\begin{array}{l}\text { Ophthalmology } \\
\text { applicants } \\
(n=203)\end{array}$ & $\begin{array}{l}\text { Non-ophthalmology } \\
\text { applicants }(n=85)\end{array}$ & p-Value \\
\hline Specialty exposure prior to medical school & $153(75.3 \%)$ & $71(83.5 \%)$ & 0.129 \\
\hline Specialty exposure during medical school prior to clinical rotations & $191(94.0 \%)$ & $79(92.9 \%)$ & 0.714 \\
\hline A clinical rotation in specialty & $201(99.0 \%)$ & $85(100 \%)$ & 0.358 \\
\hline A subinternship or away rotation in specialty & $182(89.7 \%)$ & $77(90.6 \%)$ & 0.810 \\
\hline Residency program of specialty at medical school & $175(86.2 \%)$ & $82(96.5 \%)$ & 0.010 \\
\hline Faculty mentor in specialty & $194(95.6 \%)$ & $77(90.6 \%)$ & 0.102 \\
\hline Specialty-specific interest group & $177(87.2 \%)$ & $77(90.6 \%)$ & 0.415 \\
\hline Research experience in specialty & $193(95.1 \%)$ & $72(84.7 \%)$ & 0.003 \\
\hline Volunteering/public health experience in specialty & $146(71.9 \%)$ & $70(82.3 \%)$ & 0.062 \\
\hline Family member who is a physician in specialty & $48(23.6 \%)$ & $23(27.1 \%)$ & 0.540 \\
\hline Family member (nonphysician) who works in specialty & $54(26.6 \%)$ & $19(22.4 \%)$ & 0.450 \\
\hline Personal/family history of disease unique to specialty & $93(45.8 \%)$ & $47(55.3 \%)$ & 0.142 \\
\hline
\end{tabular}

Table 3 Comparison of 2019 to 2020 ophthalmology and non-ophthalmology residency applicants with respect to factors influencing specialty choice

\begin{tabular}{|c|c|c|c|}
\hline & $\begin{array}{l}\text { Ophthalmology } \\
\text { applicants } \\
(n=203)\end{array}$ & $\begin{array}{l}\text { Non-ophthalmology } \\
\text { applicants }(n=85)\end{array}$ & $p$-Value \\
\hline Specialty exposure prior to medical school & $121(59.6 \%)$ & $57(67.0 \%)$ & 0.235 \\
\hline Specialty exposure during medical school prior to clinical rotations & $114(56.2 \%)$ & $51(60.0 \%)$ & 0.548 \\
\hline A clinical rotation in specialty & $181(89.2 \%)$ & $81(95.3 \%)$ & 0.098 \\
\hline A subinternship or away rotation in specialty & $176(86.7 \%)$ & $76(89.4 \%)$ & 0.526 \\
\hline Residency program of specialty at medical school & $144(70.9 \%)$ & $42(49.4 \%)$ & $<0.001$ \\
\hline Faculty mentor in specialty & $176(86.7 \%)$ & $62(72.9 \%)$ & 0.005 \\
\hline Specialty-specific interest group & $68(33.5 \%)$ & $23(27.1 \%)$ & 0.284 \\
\hline Research experience in specialty & $140(69.0 \%)$ & $28(32.9 \%)$ & $<0.001$ \\
\hline Volunteering/public health experience in specialty & $93(45.8 \%)$ & $41(41.2 \%)$ & 0.707 \\
\hline Family member who is a physician in specialty & $21(10.3 \%)$ & $11(12.9 \%)$ & 0.523 \\
\hline Family member (nonphysician) who works in specialty & $13(6.4 \%)$ & $2(2.4 \%)$ & 0.158 \\
\hline Personal/family history of disease unique to specialty & $31(15.3 \%)$ & $17(20.0 \%)$ & 0.326 \\
\hline Ability to perform surgeries/procedures & $188(92.6 \%)$ & $58(68.2 \%)$ & $<0.001$ \\
\hline See patients in a clinic setting & $184(90.6 \%)$ & $57(67.0 \%)$ & $<0.001$ \\
\hline Intellectual stimulation/challenging cases & $173(85.2 \%)$ & $76(89.4 \%)$ & 0.343 \\
\hline Professional satisfaction & $191(94.1 \%)$ & $78(91.8 \%)$ & 0.469 \\
\hline Personal fit with the specialty & $185(91.1 \%)$ & $81(95.3 \%)$ & 0.225 \\
\hline Work-life balance & $185(91.1 \%)$ & $65(76.5 \%)$ & $<0.001$ \\
\hline Salary or earning potential & $157(77.3 \%)$ & $59(69.4 \%)$ & 0.156 \\
\hline Job market & $127(62.6 \%)$ & $58(68.2 \%)$ & 0.360 \\
\hline Prestige or reputation & $95(46.8 \%)$ & $27(31.8 \%)$ & 0.019 \\
\hline Specific patient population or disease & $140(69.0 \%)$ & $65(76.5 \%)$ & 0.200 \\
\hline
\end{tabular}


performed approximately 30 years ago in which the most frequently cited factors were performing surgery, patient contact, life-style, and ophthalmology elective experience. ${ }^{14}$ The motivating factors identified in our study are also similar to those identified in a survey of ophthalmologists in Brazil, which found that the most frequently reported motivating factors were surgical procedures, flexible hours, personal satisfaction, and compensation. ${ }^{13}$

Exposure of medical students to ophthalmology, particularly through preclinical didactics and required clinical rotations in ophthalmology, has decreased in the past decades. ${ }^{17-19}$ Factors motivating U.S. medical students to pursue an ophthalmology residency remain largely unstudied. To our knowledge and based on a computerized search of the PubMed database, the current study is the largest to survey ophthalmology residency applicants regarding their exposure to ophthalmology in medical school and the factors that influenced them to pursue a career in ophthalmology.

The results of our study indicate that while $94.0 \%$ of ophthalmology applicants received some exposure to ophthalmology in their medical school's preclinical curriculum, a large majority (86.7\%) received fewer than 20 hours of preclinical ophthalmology education (-Table 2 ). This is consistent with previous reports that demonstrate little exposure to, and a decrease in, ophthalmology education during the preclinical years of medical school. ${ }^{4,17-19,21}$ Compared to non-ophthalmology applicants, the ophthalmology cohort had a similar prevalence of receiving any preclinical exposure to their selected specialty $(94.0 \%$ ophthalmology vs. $92.9 \%$ non-ophthalmology, $p=0.714$; - Table 2), but a noticeably greater proportion of ophthalmology applicants received fewer than 20 hours of exposure to their selected specialty in their medical school's curriculum $(86.7 \%$ ophthalmology vs. $42.4 \%$ non-ophthalmology, $p<0.001$ ). While preclinical exposure is linked to a higher likelihood of applying to ophthalmology, ${ }^{4,11,16}$ a study by Hsiao and Tatham reported that the duration of preclinical ophthalmology education was not associated with the proportion of students entering ophthalmology. ${ }^{11}$ This is consistent with our study results, which found that ophthalmology applicants decided on, or developed a strong interest in, their selected specialty before clinical rotations at a similar rate to non-ophthalmology applicants (60.6 vs. 58.8\%, respectively; $p=0.780$ ). Further, our study identified no significant difference between ophthalmology versus non-ophthalmology applicants with respect to many other exposures, such as subinternship or away rotations, interest groups, mentorship opportunities, etc., in their selected specialty. These findings suggest that although ophthalmology education in medical school required curricula has decreased over time, the decreased exposure has not resulted in a disproportionately low interest in ophthalmology compared to interest in other specialties, and that those students who do develop an interest in ophthalmology have comparable access to specialty-specific exposures outside of the required medical school curriculum. Of note, $6.0 \%$ of ophthalmology applicants did not have any preclinical exposure to ophthalmology, which highlights a potential area for improvement in medi- cal education (-Table 2). An interesting finding in both cohorts was the high rate of having a family member in the applicant's specialty (23.6\% ophthalmology vs. $27.1 \%$ non-ophthalmology, $p=0.540$ ), as well as premedical school exposure to the applicant's selected specialty $(75.3 \%$ ophthalmology vs. $83.5 \%$ non-ophthalmology, $p=0.129$; -Table 2). This supports existing literature that increased and early exposure affects an applicant's choice of specialty $4,11,16$ and highlights the significance of personal background on specialty selection.

Ophthalmology applicants, compared to non-ophthalmology applicants, were less likely to have a residency program affiliated with their medical school (86.2 vs. $96.5 \%, p=0.010$; - Table 2 ) but were more likely to cite the presence of that program to be a motivating factor for pursuing their specialty (70.9 vs. $49.4 \%, p<0.001$; - Table 3). This may be due to all medical schools having departments of common specialties (such as internal medicine and pediatrics) and fewer programs having a department for a specific surgical subspecialty like ophthalmology, and highlights the opportunities afforded by the presence of a residency program and its affiliated ophthalmology department, such as access to ophthalmology mentors and research opportunities, which were both significant motivating factors for ophthalmology applicants (-Table 3 ). Presence of an ophthalmology program has been reported previously to be associated with a greater proportion of ophthalmology residency applicants from that medical school matching, and can mitigate the apprehension of applying to a competitive specialty like ophthalmology. ${ }^{16}$ Our study findings highlight the opportunities that ophthalmology departments provide to medical students, and are consistent with reports from other recent studies regarding the substantial impact of such departments on medical student interest and success in pursuing a career in ophthalmology. ${ }^{11,16}$

Our study has several limitations. The response rate is limited, although the $61.1 \%$ response rate among non-ophthalmology applicants at our institution compares favorably to existing literature surveying medical students at a single institution (35.5-78.1\%), 2,4,10 and the $46.0 \%$ response rate of ophthalmology applicants compares favorably with recently published surveys of ophthalmology applicants (36.4$58.3 \%){ }^{23-25}$ As with any survey study, there is potential response bias. Further, ophthalmology residency applicants to Penn State may not be representative of all ophthalmology residency applicants in the United States, and the experiences and motivating factors of Penn State medical students may not be representative of those of medical students at other medical schools. While this limits the generalizability of our study to the entire applicant pool, the results of our study are intriguing and warrant further research in larger cohorts.

In conclusion, professional satisfaction and personal fit with specialty were among the most commonly cited factors influencing specialty choice among both ophthalmology and non-ophthalmology applicants. Other factors cited most frequently by ophthalmology applicants include performing 
surgeries/procedures, work-life balance, and ability to see patients in a clinic setting. Despite limited ophthalmology exposure in medical school preclinical curricula, ophthalmology applicants decided on, or developed a strong interest in, their selected specialty before clinical rotations at a rate similar to non-ophthalmology applicants.

\section{Funding}

None.

\section{Conflict of Interest}

None declared.

\section{References}

1 San Francisco Match. Ophthalmology residency match summary report 2019. Accessed June 25, 2020 at: sfmatch.org/PDFFilesDisplay/Ophthalmology_Residency_Stats_2019.pdf

2 The National Resident Matching Program. Advance data tables 2019 main residency match. Accessed June 25, 2020 at: nrmp.org/main-residency-match-data

3 Medscape. Medscape physician compensation report. 2020 Accessed June 25, 2020 at: Medscape.com/slideshow/2020-compensation-overview

4 Linz MO, Jun AS, Clever SL, Lawson SM, Sanyal A, Scott AW. Evaluation of medical students' perception of an ophthalmology career. Ophthalmology 2018;125(03):461-462

5 Lind DS, Cendan JC. Two decades of student career choice at the University of Florida: increasingly a lifestyle decision. Am Surg 2003;69(01):53-55

6 Schwartz RW, Jarecky RK, Strodel WE, Haley JV, Young B, Griffen WO Jr. Controllable lifestyle: a new factor in career choice by medical students. Acad Med 1989;64(10):606-609

7 Schmidt LE, Cooper CA, Guo WA. Factors influencing US medical students' decision to pursue surgery. J Surg Res 2016;203(01):64-74

8 Peel JK, Schlachta CM, Alkhamesi NA. A systematic review of the factors affecting choice of surgery as a career. Can J Surg 2018;61(01):58-67

9 Johnson AL, Sharma J, Chinchilli VM, et al. Why do medical students choose orthopaedics as a career? J Bone Joint Surg Am 2012;94(11):e78

10 Goltz CJ, Bachusz RC, Mancini E, Rits Y, Mattos MA, Rubin JR. Medical student career survey-vascular surgery awareness initiative. Ann Vasc Surg 2013;27(02):225-231

11 Hsiao AM, Tatham AJ. Factors at medical school influencing students' decisions to pursue a career in ophthalmology. Eye (Lond) 2018;32(06):1005-1007

12 Madani FM, Alasiri R, Howldar S, Zagzoog F, Alhibshi N. Perceptions and career expectation in ophthalmology among saudi undergraduate medical students. Middle East Afr J Ophthalmol 2018;25(3-4):142-149

13 Gameiro GR, Darcie ALF, Hazaki D, Gameiro GR, Carricondo PC. Why ophthalmology? Analysis of the motivating factors influencing the choice of ophthalmology as a career among different generations in Brazil. Clinics (São Paulo) 2019;74:e1101

14 Pankratz MJ, Helveston EM. Ophthalmology. The resident's perspective. Arch Ophthalmol 1992;110(01):37-43

15 Pianosi K, Bethune C, Hurley KF. Medical student career choice: a qualitative study of fourth-year medical students at Memorial University, Newfoundland. CMAJ Open 2016;4(02): E147-E152

16 Yamane MLM, Kassotis AS, De Moraes CG, Dagi Glass LR. Correlating ophthalmology exposure in medical school to applying and matching into an ophthalmology residency. [published online ahead of print, 2020 Apr 21]Acad Med 2020;95 (11): 1770-1776

17 Shah M, Knoch D, Waxman E. The state of ophthalmology medical student education in the United States and Canada, 2012 through 2013. Ophthalmology 2014;121(06):1160-1163

18 Quillen DA, Harper RA, Haik BG. Medical student education in ophthalmology: crisis and opportunity. Ophthalmology 2005; 112(11):1867-1868

19 Moxon NR, Goyal A, Giaconi JA, et al. The state of ophthalmology medical student education in the United States: An update. Ophthalmology 2020;127(11):1451-1453[published online ahead of print, 2020 May 10]

20 Quillen DA, Cantore WA. Impact of a 1-day ophthalmology experience on medical students. Ophthalmology 2006;113(12): 2307-2309

21 Gelston CD, Patnaik JL. Ophthalmology training and competency levels in care of patients with ophthalmic complaints in United States internal medicine, emergency medicine and family medicine residents. J Educ Eval Health Prof 2019;16:25

22 Harris PA, Taylor R, Thielke R, Payne J, Gonzalez N, Conde JG. Research electronic data capture (REDCap)-a metadata-driven methodology and workflow process for providing translational research informatics support. J Biomed Inform 2009;42(02): 377-381

23 Venincasa MJ, Cai LZ, Gedde SJ, Uhler T, Sridhar J. Current applicant perceptions of the ophthalmology residency match [published online ahead of print. JAMA Ophthalmol 2020

24 Yousuf SJ, Kwagyan J, Jones LS. Applicants' choice of an ophthalmology residency program. Ophthalmology 2013;120(02): 423-427

25 Christakis TJ, Christakis PG, Chipman ML, Christakis JT. Medical students' attitudes on diversity when applying to Toronto's ophthalmology residency program. Can J Ophthalmol 2008;43 (02):218-221 